\title{
Studies of Dielectric Constant, Dielectric Loss, Loss Tangent and Dielectric Relaxation Time of Some Halobenzene and Nitrobenzene at X-Band Microwave Frequency
}

\author{
Utpala Baruah \\ Associate Professor, Deptt. Of Physics, Namrup College
}

\begin{abstract}
The arrangement of waves or radiation in order of increasing frequencies is called electromagnetic spectrum. Frequency of microwave region is $300 \mathrm{MHz}$ to $300 \mathrm{GHz}$. Corresponding wavelength is in between $1 \mathrm{~mm}$ to $100 \mathrm{~cm}$. Here by using a microwave bench dielectric properties such as dielectric constant, dielectric loss, loss tangent and dielectric relaxationtime of Dichlorobenzene, Bromobenzene and Nitrobenzene in different temperatures at $X$ band frequrency are measured. Gopalakrishnan method is used for determination of relaxation time. Here real $\left(\epsilon^{\prime}\right)$ and imaginary $\left(\epsilon^{\prime \prime}\right)$ parts of complex dielectric constant $\left(\epsilon^{*}\right)$ were determined in the $3 \mathrm{~cm}$ microwave region for different concentration of Dichlorobenzene, Bromobenzene and Nitrobenzene in Cyclohaxene at temperatures $24^{\circ} \mathrm{C}, 33^{\circ} \mathrm{C}$ and $41^{\circ} \mathrm{C}$. The measurement were made at a frequency of $9.98 \mathrm{GHz}$. From the study of relaxation time polarity of above three compounds are studied. From the structural point of view the most interesting Dielectric Relaxation is that involving orientation polarization which depends on the internal structure of molecules and on the molecular arrangement or structure of the dielectric. Dielectric relaxation is the lag in dipole orientation behind an alternating electric field. From the study it is found that relaxation time of these solute is more in Cyclohexane then in Benzene. This behavour can be explained from the fact that Cyclohexane has more internal friction than Benzene.
\end{abstract}

Keywords: Dielectric constant, Relaxation time, Microwave X-band, Dielectric loss

\section{Introduction}

This is a report for study on the dielectric properties of Halobenzene and Nitrobenzene. At different times, different persons have studied the dielectric properties of halobenzene. The study of dielectric properties of a matter is important to understand the structure of matter.Electrical characteristics of a molecule gives important information on the distribution of charges in the molecule and provided many information about the properties of molecules which depend on its electronic distribution. Various works have been done on the study of dielectric properties of halobenzene. Study has been made on the dielectric properties of meta dichlorobenzene, bromo-benzene and nitrobenzene in cyclohexane at temperature $24^{\circ} \mathrm{C}, 33^{\circ} \mathrm{C}$ and $41^{\circ} \mathrm{C}$ at frequency $9.98 \mathrm{GHz}$. Attempts have been made to obtain information about the polarity of the molecules of the solute and the internal frictional force of the solvent under different working condition.From the structural point of view the most interesting dielectric relaxation is that involving orientation polarization which depends on the internal structure of molecules and on the molecular arrangement or structure of the dielectric. Dielectric relaxation is the lag in dipole orientation behind an alternating electric field. Under the influence of such a field the polar molecules of a system rotate towards an equilibrium distribution in molecular orientation with a corresponding dielectric polarization. When the polar molecules are very large or the frequencies of the alternating field is very high or the viscosity of the medium is very large, the rotatory motion of the molecules is not sufficiently rapid for the attainment of equilibrium with the field. The polarization then acquires a component out of phase with the field and the displacement current acquires a conductance component in phase with the field resulting in thermal dissipation of energy.

\section{Experimental Details}

An X-band microwave bench was used for the measurement of dielectric constant $\downarrow$ and the loss factor $\square^{\prime \prime}$ employing the method described by Heston et al suited for short circuit termination. The measurement were made at $9.82 \mathrm{GHz}$ with a Gunn diode powered by a Gunn power supply. The cell filled with the experimental liquid was kept vertical. The standing wave ratio's were measured by a slotted waveguide section. The temperature of the cell was controlled with the help of a thermostatic bath The method suitable for liquid or high dielectric loss is based upon the variation in the reflection co-efficient of a uniform layer of dielectric as the depth of the layer is varied by means of a moving plunger. For low loss liquids, the variation in magnitude of the reflection co-efficient with sample length is too small, for accurate measurement. The apparatus is therefore changed so as to measure the voltage standing wave ratio. 
Block diagram of the experimental arrangement

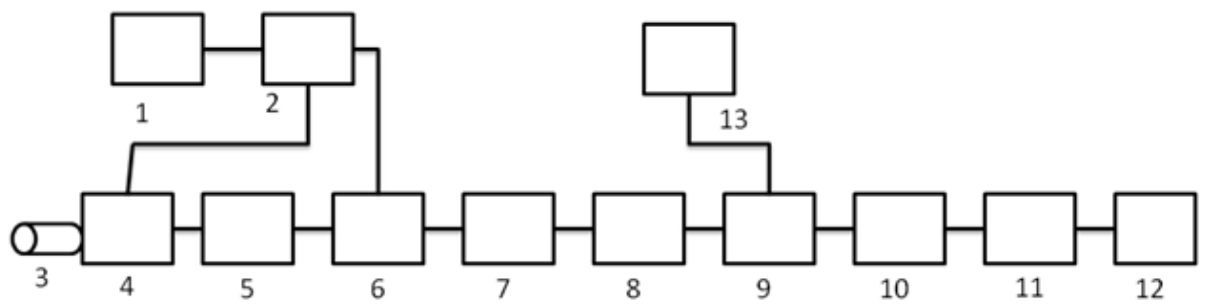

Fig: Experimental set-up for $\mathrm{X}$ band microwave test bench for studying dielectric properties of liquids

1. Voltage stabilizer

2. Gunn power supply

3. Gunn tuner

4. Gunn diode oscillator

5. Variable attenuator
6. Pin diode modulator

7. Frequency meter

8.Directional coupler

9. Crystal detector

10. E plane bend $90^{\circ}$
11. Dielectric sample holder

12.Variable short circuit plunger

13.V.S.W.R. meter.

Using standard standing wave microwave technique and following the method of Heston et all the dielectric constant $\left(\downarrow^{\prime}\right)$ and the dielectric loss $\left(\bigsqcup^{\prime \prime}\right)$ of the solution of dichlorobenzene, bromobenzene and nitrobenzene in cyclohexane was determined at $24^{\circ} \mathrm{C}, 33^{\circ} \mathrm{C}$ and $41^{\circ} \mathrm{C}$. In this experiment following equations have been used.The voltage standing wave ratio SWR is quite sensitive to small change in dielectric loss. The SWR can be represented as
$\rho_{\mathrm{n}}=\mathrm{SWR}=|\mathrm{E} \max / \mathrm{E} \min |=1+|\mathrm{G}| \mathrm{n}$
At the $\mathrm{n}^{\text {th }}$ minimum along the line where
$\mathrm{Gn}=$ Reflection coefficient
$\mathrm{E} \max =$ Voltage at the maximum point
$\mathrm{E} \min =$ Voltage at the minimum point.

The SWR may be determined by setting the detector probe at a minimum point along the guide and measuring the distances $a_{1}$ and $a_{2}$ that the probe must be moved to double the detector output. For a lossless line $a_{1}=a_{2}$ and will be given by

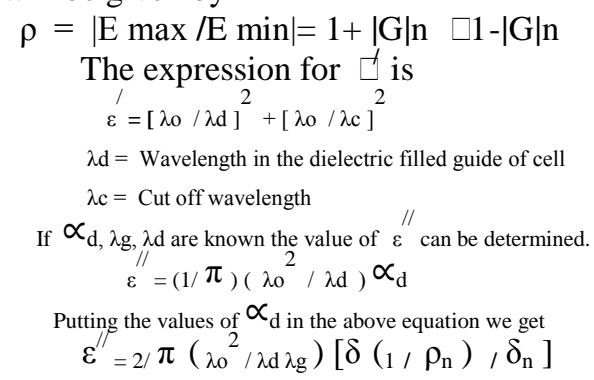

Thus the slop of $1 / \rho_{\mathrm{n}}$ Vs $\mathrm{n}$ when multiplied by ${ }_{2} / \pi\left(\lambda_{0}{ }^{2} / \lambda \mathrm{d} \lambda \mathrm{g}\right)$ will give the value

of $\varepsilon^{\prime \prime}$ since the slope is $\propto \lambda_{\mathrm{d} / 2 \mathrm{Zd}}$

Relaxation time is measured by single frequency concentration variational method of Gopala Krishna.

Considering $\quad X=\varepsilon^{\prime 2}+\varepsilon^{\prime \prime 2}-\varepsilon^{\prime}-2,\left(\varepsilon^{\prime}+2\right)^{2}+\varepsilon^{\prime / 2}$

$$
\mathrm{Y}=3 \varepsilon^{\prime \prime} /\left(\varepsilon^{\prime}+2\right)^{2}+\varepsilon^{\prime \prime 2}
$$

Writing $(\varepsilon \propto-1),(\varepsilon \propto+2)=\mathrm{P}$ it is found that $\mathrm{X}=\mathrm{P}+(1, \omega \gamma) \mathrm{Y}$

The slop of the graph $\mathrm{X}$ against $\mathrm{Y}$ will give the value of $\gamma . \gamma$ is the relaxation time.

Then considering Eyring equation free energy of activation is given by

$$
\Delta \mathrm{F}_{\varepsilon} \quad=\mathrm{RT} \log \gamma \mathrm{KT} / \mathrm{h}
$$

Using the above equation free energy of activation is measured.

Here dielectric constant $\varepsilon^{\prime}$, dielectric loss $\varepsilon^{\prime \prime}$ for meta dichlorobenzene, bromobenzene and nitrobenzene were measured at $24^{\circ} \mathrm{C}, 33^{\circ} \mathrm{C}$ and $41^{\circ} \mathrm{C}$.

From these data applying Gopala Krishna method relaxation time $\gamma$ for meta dichlorobenzene, bromobenzene and nitrobenzene at above three mentioned temperatures were measured.

\section{Result And Discussion}

The value of dielectric constant and dielectric loss of meta dichlorobenzene in benzene solution at temperature $20^{\circ} \mathrm{C}$ and frequency $9.06 \mathrm{GHz}$ as obtained by Mansingh and Mclay (1968) are $\varepsilon^{\prime}=2.36,2.38,2.46$ and $\varepsilon^{\prime \prime}=0.048,0.053,0.086$ for weight fractions $0.0554,0.0811$ and 0.1283 respectively. Then Modan (1975) has presented the values of dielectric loss. 
The values at $25^{\circ} \mathrm{C}, \varepsilon^{\prime \prime}=0.033,0.029,0.018$ and $\tan \delta=0.0147,0.0128,0.0086,0.0053$. Here in this experiment the values of dielectric constant $\varepsilon^{\prime}$, dielectric loss $\varepsilon^{\prime \prime}$ and loss tangent are given in table-I, table-II, and table-III.

Table I: The dielectric constant $\varepsilon^{\prime}$, the dielectric loss $\varepsilon^{\prime \prime}$ and loss tangent Tan $\delta$ for meta dichlorobenzene

\begin{tabular}{|l|l|l|l|}
\hline Temperature & $\square^{\prime}$ & $\square^{\prime \prime}$ & Tand \\
\hline $24^{\circ} \mathrm{C}$ & 2.09 & 0.176 & 0.084 \\
\hline $33^{\circ} \mathrm{C}$ & 2.05 & 0.133 & 0.064 \\
\hline $41^{\circ} \mathrm{C}$ & 2.03 & 0.124 & 0.061 \\
\hline
\end{tabular}

Table II: The dielectric constant $\varepsilon^{\prime}$, dielectric loss $\varepsilon^{\prime \prime}$ and loss tangent Tan $\delta$ for bromobenzene

\begin{tabular}{|l|l|l|l|}
\hline Temperature & \multicolumn{1}{|c|}{$\square$} & $\square^{\prime \prime}$ & Tan \\
\hline $24^{\circ} \mathrm{C}$ & 2.05 & 0.081 & 0.034 \\
\hline $33^{\circ} \mathrm{C}$ & 2.03 & 0.062 & 0.031 \\
\hline $41^{\circ} \mathrm{C}$ & 2.04 & 0.054 & 0.026 \\
\hline
\end{tabular}

Table III: The dielectric constant $\varepsilon^{\prime}$, dielectric loss $\varepsilon^{\prime \prime}$ and loss tangent Tan $\delta$ for nitrobenzene

\begin{tabular}{|l|l|l|l|}
\hline Temperature & $\square$ & $\square^{\prime \prime}$ & Tan $\square$ \\
\hline $24^{\circ} \mathrm{C}$ & 2.6 & 0.50 & 0.192 \\
\hline $33^{\circ} \mathrm{C}$ & 2.4 & 0.38 & 0.158 \\
\hline $41^{\circ} \mathrm{C}$ & 2.2 & 0.16 & 0.073 \\
\hline
\end{tabular}

Table-IV represent the variation of relaxation time with temperature of Bromobenzene, Nitrobenzene and Chlorbenzene.

Table IV: Relaxation time for Bromobenzene at different temperature

\begin{tabular}{|l|l|}
\hline Temperature & Relaxation time (T ps) \\
\hline $24^{\circ} \mathrm{C}$ & 8.0 \\
\hline $33^{\circ} \mathrm{C}$ & 4.8 \\
\hline $41^{\circ} \mathrm{C}$ & 3.8 \\
\hline
\end{tabular}

Relaxation time for Nitrobenzene at different temperature

\begin{tabular}{|l|l|}
\hline Temperature & Relaxation time, T ps \\
\hline $24^{\circ} \mathrm{C}$ & 12.2 \\
\hline $33^{\circ} \mathrm{C}$ & 10.7 \\
\hline $41^{\circ} \mathrm{C}$ & 8.0 \\
\hline
\end{tabular}

Relaxation time and for chlorobenzene at different temperature

\begin{tabular}{|l|l|}
\hline Temperature & T ps \\
\hline $24^{\circ} \mathrm{C}$ & 8.9 \\
\hline $33^{\circ} \mathrm{C}$ & 5.6 \\
\hline $41^{\circ} \mathrm{C}$ & 4.5 \\
\hline
\end{tabular}

Relaxation time for meta dichlorobenzene were $8.9 \mathrm{ps}, 5.6 \mathrm{ps}, 4.5 \mathrm{ps}$ at temperature $24^{\circ} \mathrm{C}, 33^{\circ} \mathrm{C}$ and $41^{\circ} \mathrm{C}$ respectively. Again Relaxation time for bromobenzene were $8 \mathrm{ps}, 4.8 \mathrm{ps}$ and $3.8 \mathrm{ps}$ at temperature $24^{\circ} \mathrm{C}$, $33^{\circ} \mathrm{C}$ and $41^{\circ} \mathrm{C}$ respectively. Similarly the relaxation time of Nitrobenzene were $12.2 \mathrm{ps}, 10.7 \mathrm{ps}$ and $8 \mathrm{ps}$ at $24^{\circ} \mathrm{C}, 33^{\circ} \mathrm{C}$ and $41^{\circ} \mathrm{C}$ respectively. It is seen that the literature values obtained by different workers exhibit only fair agreement with one another. We have seen that the values obtained find a reasonable agreement with the available literature values.

The values of dielectric constant $\varepsilon^{\prime}$ and dielectric loss $\varepsilon^{\prime \prime}$ show significant variation as the concentration of dichlorobenzene changes. Here Meta Dichlorobenzene, Bromobenzene and Nitrobenzene are taken as solute and cyclohexane as the solvent. 
By comparing the result obtained from this experiment with the result found in earlier experiments taking Benzene as solvent it is found that -

1. Relaxation time of the solute is more in Cyclohexane than in Benzene. This behavior can be explained from the fact that Cyclohexane has more internal friction than Benzene.

2. The value of $\gamma$ for Dichloro metabenzene at a particular temperature is more than the $\gamma$ for Bromobenzene.Similariy Nitrobenzene has more value than Halobenzene The higher value of $\gamma$ implies that the polarity of Dichloro metabenzene is more than the polarity of Bromo-Benzene.Similarly the polarity of Nitrobenzene is more than Halobenzene.

\section{Conclusion}

From the observed values of relaxation time of meta dichlorobenzene, bromo benzene and nitrobenzene it is seen that the value of relaxation time decreases with the increase of temperature. The behavior of the relaxation process can be discussed in terms of the transition state theory which treats the dielectric relaxation as a rate process. There is no dependence of relaxation time on concentration hence there is no evidence for the dipole interaction in the dilute solution that have been studied. The variation of relaxation time is due to the variation of the polarity as well as the molecular size of the compounds.

\section{References}

[1]. Bahal B.S. and Bahal Arun, Advance Organic Chemistry

[2]. Baruah B.N. and Baishya B, Indian J. Pure and Applied Physics (1982) 1003-1004.

[3]. Gupta P.C. Arrowatia M.L. and Sissodia M.L., Indian J. Pure and Applied Physics 16 (1978) 707.

[4]. Kalyanraman S.B. and Vasuhi P.S., J. Insturn Soc. India 29(1) (1999) 13-17.

[5]. Mansing A and Melay Dvaid B., Ca. J. Physics. 46(1968) 2745.

[6]. Sharma G.L. and Gandhi J.N. (1989), India J. physics 64B (4) 1990, 272-283.

[7]. Smyth G.P., Dielectric behavior and Structure.

[8]. B.N. Baruah and B. Baishya, J. Assam Sci. Soc. 26 (2); 32-37, 1984. 